\title{
Expanding mobile information service needs to improve quality of life: A cross-temporal comparison of Japanese students
}

\author{
Fumiyo N. Kondo *, Qazi Mahdia Ghyas ${ }^{\dagger}$
}

\begin{abstract}
The purpose of this paper is to identify how the use of mobile information services (MIS) contributes to the quality of life (QoL) of young Japanese users. We examined the relationship between individual life domains and the overall QoL via the bottom-up spillover theory. Questionnaire surveys were conducted online among young Japanese mobile users studying in a university. We obtained data from 107 effective respondents. Comprehensive analyses of the relationships between constructs were conducted using partial least squares structure equation modeling (PLSSEM), which is an analytical method considered appropriate for research models of a non-established nature, many constructs, and a small sample size. The results of this study clearly indicated that the relationship between individual contribution and overall contribution is valid and reliable. Leisure life had the greatest influence on overall contribution among Japanese young adults. Further, there were some changes between 2013 and 2015 with respect to more positive and significant individual life domains, which are as follows in descending order: cultural life, community life, informational life, home-healthcare life, financial life, trustworthy life, health life, and safety life.
\end{abstract}

Keywords: Bottom-up spillover theory, Mobile information services, PLS-SEM, Quality of Life.

\section{Introduction}

Studies on mobile computing have often utilized satisfaction [1] and intention to use [2] to examine the impact of mobile computing technologies on outcome. These variables measure users' feelings or attitudes at the time of using a system, rather than the impact of the system on their overall quality of life (QoL). Very few studies directly address the impact of mobile information services (MIS) on overall QoL. Reference [3] presented a picture of conditions around the world with respect to such interrelated domains of QoL. Reference [4] proposed eleven relationships between individual contribution and overall contribution of QoL in Korea and Japan and found that some of them had a stronger influence on overall contribution. Reference [5] analyzed the relationship between MIS and QoL in Japan.

\footnotetext{
* University of Tsukuba, Ibaraki, Japan

$\dagger$ International University of Scholars, Dhaka, Bangladesh
} 
The performance of a digital information system (IS) is usually measured in terms of how effective it is at achieving specific need and goals [6] or how satisfying it is to use for particular tasks [7]. One of the goals of any technology should be to increase the quality of its users' lives [8]. The needs and uses of MIS may differ on the basis of age and the timing of technology diffusion. If service needs continue to differ after considering these two factors, mobile companies need to vary their international marketing strategies and tactics to fulfill these needs., mobile companies need to vary their international marketing strategies and tactics to address these differences Studies conducted on a cross-temporal basis on how young people's QoL has improved owing to mobile technology are also limited. At present, we do not know the domains of a young user's life that influence their overall QoL in different time periods.

The motivation behind this study is to successfully apply the bottom-up spillover theory to connect the MIS market, an important emerging market, with QoL research via a cross-temporal study, which has not been previously conducted. This study considers life domains that have a significant influence on overall QoL after adjusting for time differences. It explains the importance of adjusting for sample characteristics such as gender and age and focusing on time differences, and attempts to identify mobile services that will improve the QoL of young users the most for the current data. It explores other potential ways to use the two measures, Overall Contribution and Individual Contribution. In practice, this will help companies allocate resources to the life domains that are most relevant to young users' overall QoL.

The authors recognize the importance of revisiting the same problem by [5] with updated MIS data, using the same theory to compare the current with the past. This is because they are dealing with an important emerging market that is expected to change over time and is worth reexamining. As a result, the findings of this study would be useful to MIS providers in emerging markets, in which they consider discussing the major differences over time in terms of their changing contributions of individual life domains to overall quality of life.

The main goal of this study is to continue to construct a theoretical model that can reliably and validly measure the relationship between MIS and QoL by conducting a cross-temporal study, and test the hypothesis of positive coefficients for each variable. We examine the contribution of life domains to Japanese students' "QoL" after using MIS in an expanding mobile market.

The reminder of this paper is organized as follows. The next section describes the theoretical background, including overall QoL, individual life domains, the bottom-up spillover theory, and its contribution to QoL. The third section describes the analysis and consists of the data, methodology, and results. The remaining sections present a summary of the discussion, conclusions, and the implications and directions for future research.

\section{Theoretical Background}

\subsection{Quality of Life (QoL)}

The term QoL has been defined differently by various scholars. Reference [9] defines QoL as the "necessary conditions for happiness," while [10] defines it as subjective well-being. There are many terms that are used to represent well-being, and the commonly used ones are QoL, standard of living, human well-being, and welfare. QoL is a measure of how happy people are or how fulfilled they are in terms of their various wants and needs.

Studies of QoL have been conducted in diverse areas, including marketing, health, and education (e.g., [11], [12], [13]). However, only a few studies have been conducted in the area of telecommunication services for young users. Here, we will attempt to measure the contribution of MIS empirically and provide a theoretical model that explicitly links MIS and QoL, for young 
users in Japan.

\subsection{Individual Life Domains}

QoL researchers have identified several distinct life domains that encompass the various places, things, activities, roles, and relationships in which a person typically finds himself or herself involved [14]. They propose that people experience and store the various events of their life in distinct domains such as leisure life, family life, friend life, cultural life, work life, community life, consumer life, financial life, health life, safety life, and self life. These eleven life domains have been examined with respect to mobile data services (MDS) by [4], which pertains to Japan and Korea. The other four life domains are educational life [14], [15], home-healthcare life [16], trustworthy life [16], and informational life [17].

We are more interested in understanding how the use of MIS contributes to QoL than in understanding how generally satisfied people are with their lives. As the use of mobile phones have blurred the boundaries between home and work [18], MIS can be used irrespective of time and place [19]. Therefore, MIS has the potential to affect many life domains, depending on the timing and context. Moreover, we want to clarify the domains of MIS that are most relevant to overall QoL.

\subsection{Bottom-up spillover theory}

It is the responsibility of the MIS to contribute to the QoL of its users, which is a general sense of well-being, life improvement, general happiness, beyond meeting market demand (included in [20]). In other words, MIS businesses are now expected to contribute to the social as well as economic welfare of society. Today, mobile marketing's primary focus can be viewed as enhancing human well-being by satisfying user needs [21]. MIS businesses cannot simply sell services they "happen" to make. As a user's behavior is guided or motivated by a sequence of needs [22], mobile businesses need to engage in research to understand human needs and wants, and deliver services that can satisfy important needs in ways that will enhance the QoL of a certain user segment. QoL is an objective variable to explain how MIS are Improving overall QoL by fulfilling the needs in users' individual life domains, which is a social outcome for a customer. If a firm wants to make long-term profits, it should focus on users' QoL.

\section{MIS business}

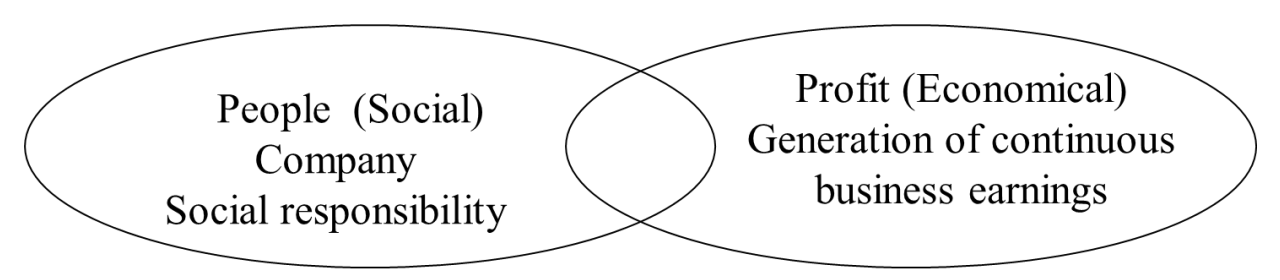

\section{Socio-economic}

Figure 1: (Source) Sustainable business network (2003) and Ericsson networked society city index 
The bottom-up spillover theory [14] explains the relationship between individual life domains and the overall QoL. Life satisfaction can be explained and predicted from the satisfaction with experiences within different life domains. For example, people may feel satisfied with their life overall after using MIS as a direct result of their satisfaction with their job, family, friends, and material possessions. The theory indicates that QoL in individual domains has a spillover effect on the overall QoL. In other words, happiness in subordinate individual life domains can spill over to produce superordinate overall happiness [14]. The bottom-up spillover theory has been concretized into the satisfaction hierarchy model. The premise of this model is that overall life satisfaction is functionally related to satisfaction within each of the individual life domains, which can be measured in terms of satisfaction with specific events in each life domain [23].

\subsection{Contribution to QoL}

The basic premise of the bottom-up spillover theory is that satisfaction levels within individual life domains affect the overall level of life satisfaction [23]. When we apply the bottom-up spillover theory to MIS, we replace satisfaction with improvement on the aspects of QoL. Figure 2 illustrates the relationship between Individual Contribution and Overall Contribution in our research model. The bottom layer of our model represents the contribution of MIS to QoL in those domains (henceforth, Individual Contribution). The contribution of MIS to the quality of individual life domains can be measured by the perceived contribution of specific MIS-use experiences in that domain. Let X1 through X3 in Figure 2 represent the formative measurements (or indicators) for the underlined latent variable (construct) of Life Domain 1, for example, Community Life. Likewise, the measurements X4 through X45 represent the other fourteen constructs of life domains, respectively. The top layer in our model represents the specific contribution of MIS to overall QoL (henceforth, Overall Contribution). Like Individual Contribution, Overall Contribution is conceptualized as the perceived contribution of MIS services to overall QoL. Y1 through Y4 in Figure 2 are the reflective measurements for Overall Life, namely, OVR 1, OVR 2, OVR 3, and OVR 4 in Table 2. The measurements are presented in the APPENDIX.

Prior studies suggest that information technology (IT) does have an influence on users' QoL. For example, [24]'s study of adoption behavior for hedonic systems implied that IT may influence leisure or culture life. Reference [25] explained users' continuance behavior in online banking systems, showing that such systems affect QoL in the financial life domain. Reference [4] measured the contribution of MDS technology to users' QoL, and examined eleven individual life domains for Korean and Japanese respondents. By including the additional four domains, [8] examined the following 15 life domains for young Japanese respondents: community life, consumer life, cultural life, educational life, family life, financial life, friend life, health life, health monitoring life, informational life, leisure life, safety life, self life, trustworthy life, and work life. We examined the same 15 life domains as those of [8] because we obtained another sample on the same university and needed to observe how changes in the relationship among constructs occur over time. Our measures concern the spillover of contributions to QoL by the usage of MIS. Therefore, the contributions of MIS to QoL within individual domains are specified to express their 
influence on the contribution of MIS to overall QoL in a model. We used two control variables, namely, age and gender, to adjust for differences in the values of the two variables. Our final research model is shown in Figure 2. We hypothesized that the improvement of QoL in each life domain by using MIS positively influences overall QoL for young Japanese mobile users.

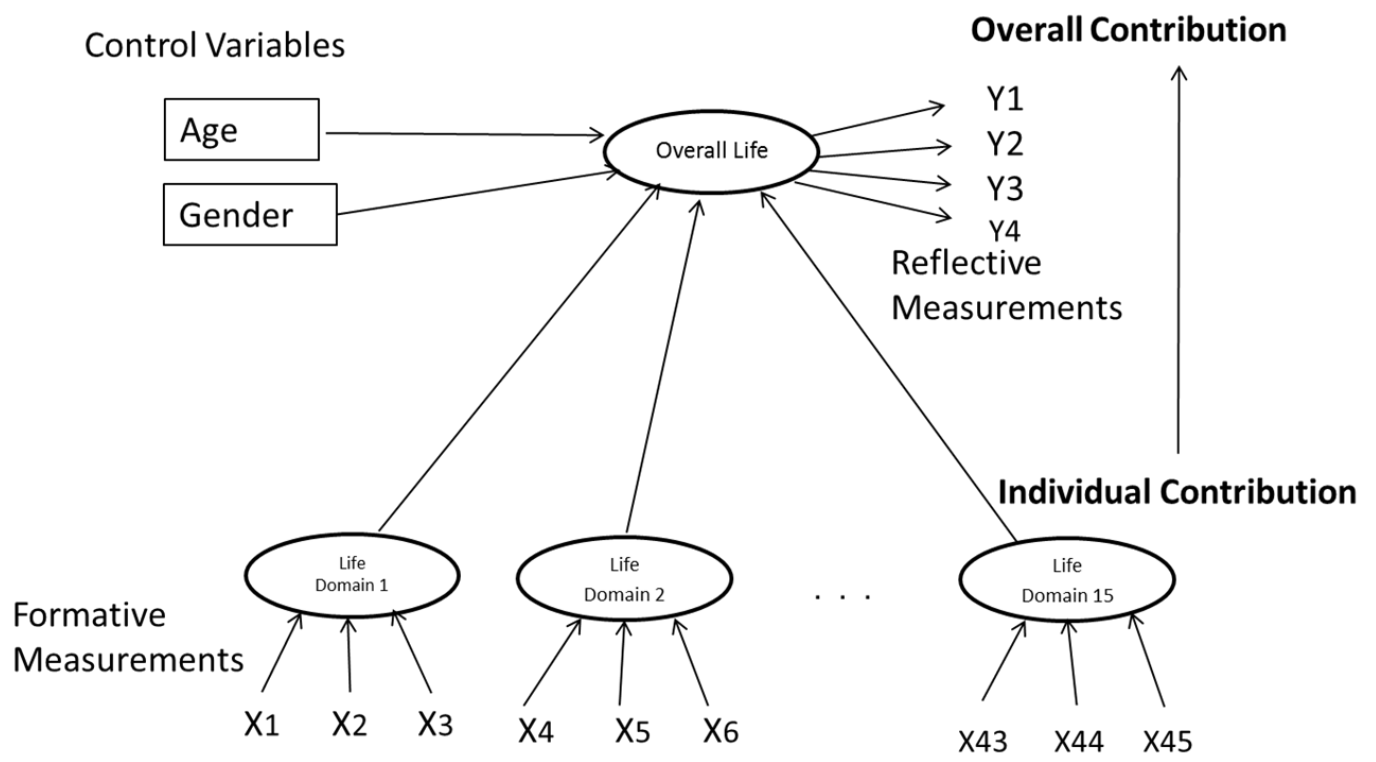

Figure 2: Relationship between individual contribution and overall contribution

\section{Theoretical Background}

\subsection{Data}

A survey involving 112 mobile phone users at a university in Ibaraki, Japan, was conducted during November-December 2015. An online questionnaire was distributed. We used the responses from users aged 19 to 29 years for this research. The major respondents were young adults since the mobile phone has become a key information technology tool for the youth [26]. Our participants were young Japanese users of MIS via mobile phone with Internet convergence. Most of our sample consisted of smartphone users. We eliminated some responses that had missing values. After this elimination, there were 107 respondents for the purpose of the analysis in Japan in 2015 (Table 1).

Questions measuring Individual Contribution in the 15 life domains were based on MIS-user experiences. Our survey items for eleven life domains were adapted from [4] and those of four life domains were adapted from [14], [16], and [17]. We chose to use the formative indicators elicited to reflect concrete user experiences with MIS because our theoretical foundation, the bottom-up spillover theory required highly specific events and experiences at the bottom of the improvement hierarchy model. The differences in gender and age could affect the results. Therefore, our model used two control variables, namely, age and gender, as well as the same 15 life 
domains as those of [8] to adjust for differences in the demographics between 2013 and 2015. The model is illustrated in Figure 2. Demographic information about the effective participants is presented in Table 1. Our online survey was conducted among university students in 2015, and that of [8] was conducted in 2013.

The authors chose the variables of age for mobile information services as control variables because the ratio of age is very different between 2013 data and 2015 data and gender because for the usage of MIS between different genders are reported to be different in many studies. The other attributes, i.e. nationality and living with his/her family member, can be control variables for this study. However, the authors do not choose them due to less priority as control variables. For example, students use mobile devices in Japan and carriers and infrastructure of mobile information services should be similar within Japan. Therefore, there will be no remarkable differences among students with different nationality living in Japan. Also, students have own mobile devices, so that living with his/her family member will not influence on usage of MIS. In this way, we considered those variables as less important.

Subjects were asked to rate how much they believed that each specific experience of using MIS contributes to QoL in the corresponding individual life domains. We constructed questions measuring Overall Contribution of MIS to QoL as reflective indicators based on the Improvement with Life Scale (IWLS).

Table 1: Demographics of Respondents by Year

\begin{tabular}{|c|l|r|r|r|r|r|r|}
\hline \multicolumn{2}{|l|}{ Category } & \multicolumn{2}{|c|}{2015} & \multicolumn{2}{|c|}{2013} & \multicolumn{2}{|c|}{$2005-2006^{*}$} \\
\hline \multirow{2}{*}{ Gender } & Male & 80 & $76 \%$ & 137 & $72 \%$ & 569 & $55 \%$ \\
\cline { 2 - 8 } & Female & 25 & $24 \%$ & 52 & $28 \%$ & 469 & $45 \%$ \\
\hline \multirow{3}{*}{ Age } & 19 years old or younger & 52 & $49 \%$ & 32 & $17 \%$ & 5 & $1 \%$ \\
\cline { 2 - 8 } & $20-29$ years old & 53 & $51 \%$ & 151 & $80 \%$ & 174 & $16 \%$ \\
\cline { 2 - 8 } & $30-39$ years old & N/A & N/A & 6 & $3 \%$ & 462 & $45 \%$ \\
\cline { 2 - 8 } & 40 years old or older & N/A & N/A & N/A & N/A & 397 & $38 \%$ \\
\hline
\end{tabular}

*: Choi et al. (2007)

\subsection{Analytical Method}

We use a component-based structural analysis method, that is, the partial least squares structure equation modelling (PLS-SEM), instead of the conventional covariance-based structure equation modelling (CB-SEM). PLS analysis is particularly suited to cases in which CB-SEM reaches its limits, such as when the number of items (indicators) per latent variable becomes excessively large or when the sample size is small. In CB-SEM, the normality of data distribution is assumed, and each construct should basically have more than three items to avoid the identification problem. Thus, PLS-SEM becomes a good alternative to CB-SEM in the following situations: (1) sample size is small; (2) applications have little available theory; (3) predictive accuracy is paramount; (4) correct model specification cannot be ensured. However, the PLS method has several advantages. Constructs with less than three indicators can be handled since identification issues have been overcome. In contrast, constructs with a larger number of indicator variables, e.g., more than 50 items can be handled. The PLS method does not assume the normality of data distribution since its application is performed by the non-parametric method. It handles more 
complex models easily and efficiently. While CB-SEM needs a bigger sample size, PLS-SEM can make do with a smaller sample size. PLS-SEM has more exploratory characteristics, but CBSEM has more testing and verifying characteristics. Therefore, PLS-SEM is chosen when theories are not well developed. Meanwhile, PLS-SEM has some weaknesses: (1) high-valued structural path coefficients are necessary if the sample size is small; (2) the problem of multicollinearity exists if not handled well; (3) since the arrows are always single headed, it cannot model undirected correlation; (4) a potential lack of complete consistency in scores on latent variables may result in biased component estimation, loadings, and path coefficients; (5) it may create large mean square errors in the estimation of path coefficient loading.

The validity and reliability of the measures were tested using PLS, a method well suited to handle both formative indicators (for Individual Contribution) and reflective indicators (for Overall Contribution) [28]. The research models were analyzed for Japan in 2015 via PLS by the statistical software, smart-PLS version 2.0 M3. Reference [4] also used PLS to construct a theory of MDS contribution to QoL with respect to Japanese and Korean mobile users.

\subsection{Validity and Reliability of the Measures}

There are two types of measurement scales in SEM: formative and reflective. In the research by [4], both reflective and formative measurements were present in the same model. PLS is appropriate for handling both formative indicators as well as reflective indicators [28]. Since the criteria for assessing reflective and formative constructs are different, we assessed the two types of constructs separately. In PLS, loadings represent the influence of individual scale items on reflective constructs [29]. With respect to reflective measurement scales, their indicator reliability, internal consistency reliability, and discriminant validity should be fully examined [30]. Therefore, to assess the reliability and validity of the reflective constructs, we checked the factor loadings as confirmatory factor analysis, composite reliability (CR), and average variance extracted (AVE) for Overall Contribution in Table 2. Here, the measurements, OVR 1 through OVR 4, which correspond to Y1 through Y4 in Figure 2, stand for the measurements of the Overall Life Domain. The results indicate that all the measuring items secure convergent validity at the indicator and construct levels and the internal consistency of the indicators. In PLS, weights represent the comparable influence on formative constructs [29]. Thus, we examine the weight, multicollinearity, and discriminant validity of the formative construct. In a formative measurement model, the problem of multicollinearity on indicators may occur if the indicators are highly correlated with each other. We have generated variance inflation factors (VIF) and Tolerance values for multicollinearity checking.

Table 2: Reliability and validity of overall contribution in 2015

\begin{tabular}{|l|r|r|r|r|}
\hline \multirow{2}{*}{ Evaluation Criteria } & \multicolumn{4}{|c|}{ Reflective Indicator (Overall Contribution) } \\
\cline { 2 - 5 } & OVR 1 & OVR 2 & OVR 3 & OVR 4 \\
\hline $\mathrm{CR} \geq 0.70$ & \multicolumn{4}{|c|}{0.91} \\
\hline AVE $\geq 0.50$ & 0.92 & 0.87 & 0.91 & 0.68 \\
\hline Loading $\geq 0.50$ & 106.90 & 43.78 & 84.95 & 9.74 \\
\hline t-value at $\mathrm{p}<0.001$ &
\end{tabular}

Of the collinearity statistics, VIF of formative constructs of the Individual Domain for Japan in 2015 were less than 2.4 and lower than the criterion of 5, indicating that multicollinearity is not severe [30]. We used the standard bootstrapping procedure of 5000 samples recommended 
by [30] to test convergent validity. The weights and t-statistics of all formative indicators were found to bear significant relationships at the $1 \%$ significance level within the corresponding life domains. Moreover, the weights for each of the question items were not always positive. We excluded the question items with negative weights that have reversed signs due to its' nature of out-of- date questions such as the one related to "Ring-tones."

\section{Result}

We tested the nomological validity of the model with 15 life domains by PLS-SEM, which is useful for SEM, especially when the number of participants is limited or error distribution is nonnormal. We tested whether the domain-specific contribution of MIS to QoL had a significant relationship with Overall Contribution of MIS to QoL. Table 3 shows that the coefficient of determination, R-squared was 0.65 in 2015, which increased from 0.58 in 2013, and which indicates an acceptable fit. This means that the 15 individual life domains moderately explain $65 \%$ of the variance in Overall Contribution.

Meanwhile, predictive relevance is another aspect that can be explored for the inner model. Table 3 shows that the obtained Stone-Geisser's $\left(Q^{2}\right)$ value (i.e., cross-validated redundancy measures) for Overall Contribution was 0.37 in 2015, which indicates a large predictive relevance. Regarding the overall quality of the PLS structural model, we computed the value of the goodness-of-fit (GoF) [31], shown in Table 3. The GoF and R-squared values for 2015 were larger than those for 2013, resulting in a better model fitting. Therefore, the 15 life domains in our model are useful to forecast Overall Life, and Overall Contribution and Individual Contribution were found to have appropriate levels of reliability and validity for Japan.

Table 3: Model selection criteria by year

\begin{tabular}{|l|c|c|c|}
\hline Year & $\begin{array}{c}\mathbf{R}^{2} \text { of En- } \\
\text { dogenous } \\
\text { Construct }\end{array}$ & $\mathbf{Q}^{\mathbf{2}}$ & GoF \\
\hline 2013 & 0.58 & 0.42 & 0.67 \\
\hline 2015 & 0.65 & 0.37 & 0.69 \\
\hline
\end{tabular}

According to the theoretical model by [4], the Individual Contributions of MIS influence the Overall Contributions of MIS, suggesting that the feeling of improvement in QoL by MIS users in the individual domains can lead to a feeling of improvement in their overall QoL (close to ideal life, improvements in life, satisfaction in life, and achievements in life). To explore which of 15 life domains are more closely related to the overall QoL, we conducted a PLS analysis of 5000 samples using the Bootstrap method, recommended by [30]. We estimated the path coefficients between Individual Contribution and Overall Contribution, which are shown in Table 4.

The results of the 2015 data indicate that contributions to 12 individual life domains had significant impacts on the overall contribution of MIS, with an increasing number of significant coefficients from six in 2013 to twelve in 2015. Leisure Life has the highest influence on Overall Contribution with $\beta=0.27, \mathrm{t}=4.15, \mathrm{p}<0.001$ followed by Cultural Life $(\beta=0.25, \mathrm{t}=4.86, \mathrm{p}<$ $0.001)$; Community Life $(\beta=0.22, \mathrm{t}=4.39, \mathrm{p}<0.001)$; and Informational Life $(\beta=0.20, \mathrm{t}=3.84$, $\mathrm{p}<0.001)$. With the exception of Community Life, the other three variables were statistically significant in 2013 as well, and were found to be stable and significant variables. Other positively 
significant individual life domains were Home-healthcare, Financial, Trustworthy, Health, and Safety. These variables became newly statistically significant probably owing to the increasing need for information services in these domains. However, there were three negatively significant variables, namely, Consumer Life, Self Life, and Educational Life. Since we used formative indicators, weight coefficients can be calculated as negative or positive.

Table 4: Comparison of sample differences with Choi et al. (2007) for Japan in 2015

\begin{tabular}{|c|c|c|c|c|c|c|}
\hline \multirow{2}{*}{$\begin{array}{l}\text { Hypotheses } \\
\text { Leisure Life--> Overall Life }\end{array}$} & \multicolumn{2}{|l|}{2015} & \multicolumn{2}{|l|}{2013} & \multicolumn{2}{|c|}{$\begin{array}{c}\text { Japan } \\
\text { (Choi et al. } \\
\text { 2007) }\end{array}$} \\
\hline & 0.27 * & $* * *$ & 0.15 * & $* * *$ & 0.11 & $* * *$ \\
\hline Cultural Life --> Overall Life & $0.25 *$ & $* * *$ & $0.18 *$ & $* * *$ & 0.12 & $* * *$ \\
\hline Community Life --> Overall life & $0.22 *$ & $* * *$ & 0.08 & & 0.08 & \\
\hline Informational Life --> Overall Life & $0.20 *$ & $* * *$ & $0.19 *$ & $* * *$ & $\mathrm{~N} / \mathrm{A}$ & \\
\hline Home-healthcare Life --> Overall Life & $0.14 *$ & $* * *$ & 0.09 & & $\mathrm{~N} / \mathrm{A}$ & \\
\hline Financial Life --> Overall Life & $0.13 *$ & $* * *$ & 0 & & 0.23 & $* * *$ \\
\hline Trustworthy Life --> Overall Life & $0.12 *$ & $* * *$ & -0.02 & & $\mathrm{~N} / \mathrm{A}$ & \\
\hline Health Life --> Overall Life & 0.11 & $* *$ & 0.1 & & -0.00 & \\
\hline Safety Life --> Overall Life & 0.11 & $* *$ & -0.01 & & 0.02 & \\
\hline Family Life --> Overall Life & 0.11 & & -0.08 & & 0.02 & \\
\hline Work Life --> Overall Life & -0.08 & & $0.1 *$ & $* * *$ & -0.06 & $* * *$ \\
\hline Friend Life --> Overall Life & -0.09 & & $0.17 *$ & $* * *$ & 0.03 & \\
\hline Self Life --> Overall Life & $-0.10 *$ & $* * *$ & -0.08 & & 0.37 & $* * *$ \\
\hline Consumer Life --> Overall Life & $-0.11 *$ & $* * *$ & 0.07 & & 0.09 & \\
\hline Educational Life --> Overall Life & $-0.14 *$ & $* * *$ & $0.11 *$ & $* * *$ & $\mathrm{~N} / \mathrm{A}$ & \\
\hline Age & 0.03 & & 0.02 & & 0.63 & \\
\hline Gender & -0.05 & & -0.02 & & $\mathrm{~N} / \mathrm{A}$ & \\
\hline R2 value & 0.65 & & 0.58 & & 0.51 & \\
\hline
\end{tabular}

(note: N/A represents "Not Applicable;" ***p <0.001; **p <0.05; *p <0.1.)

In particular, Educational Life does not have a stable effect on overall QoL because the sign of coefficients reversed, from positive in 2013 to negative in 2015. Since we used formative indicators, weight coefficients can be calculated as negative or positive.

\section{$5 \quad$ Findings and Discussions}

This study operationalized 15 life domains to measure the contribution of MIS to QoL among young Japanese students. We successfully applied the bottom-up spillover theory to explain the use of MIS by young Japanese users. This study has two layers (Bottom layer: Individual Contribution; Top layer: Overall Contribution) to measure the contribution of MIS to users' QoL. Results from the two consecutive studies clearly indicate that the two layers are valid and reliable in the bottom-up spillover theory. As users perceived a greater contribution of MIS in specific life domains, they also perceived a greater contribution of MIS to their overall QoL. 
We found that of our 15 life domains, the following four key life domains had a greater impact on Overall Contribution among young Japanese users than the other significant life domains: Leisure, Cultural, Informational, and Community. The first three, namely, Leisure, Cultural, and Informational life domains are significant, leading to the same stable results as those in [5] for 2015. The last domain, Community Life, became newly significant. Other positively significant individual life domains of the QoL were Home-healthcare, Financial, Trustworthy, Health, and Safety. We showed that the perceived contribution of user experiences for the five life domains were found to be the additional key domains for young Japanese MIS users.

However, the three variables that had a negative and significant effect on overall QoL were Consumer Life, Self Life, and Educational Life. Since we used formative indicators, weight coefficients were calculated as negative or positive. In particular, Educational life did not have a stable effect on overall QoL because the sign of the coefficient changed from positive in 2013 to negative in 2015. This variable had a negative weight for one measurement that was eliminated from the model, but positive weights for the other measurements: "to be able to view education programs via the MIS in the absence of my PC will improve my educational life." This may be a result of the differences in user responses, which depends on the advancement of information technology. Consumer Life and Self Life had non-significant effects on overall QoL in 2013, and negatively significant effects on overall QoL in 2015. Some measurements, which were eliminated from the model, for these two constructs also had the problem of negative weights; however, they had positive weights for the other measurements. Measurements with negative weights were as follows: (1) Consumer Life: "Searching for information on goods I want to buy through MIS improves my life as a consumer;" "Exchanging goods over MIS improves my life as a consumer;" (2) Self Life: "Downloading the latest ring-tones and logos over MIS increases my self-esteem."

The 2015 results are different compared to those for 2013. The effects of friend life and work life on the overall QoL are significant in 2013, but not significant in 2015. This is possibly because of sample characteristics such as age ratio. While $49 \%$ of the respondents in 2015 were 19 years old or younger, that is, first or second year university students, $80 \%$ of the respondents in 2013 were between 20 and 29 years old. It may be reasonable to assume that, for work life or friend life, it takes time for first or second year students to adjust their lives to the surrounding environments as they need to establish real relationships with new acquaintances. In such environments the use of MIS, that is, efficient communication needs in those life domains, might not be too effective, thus leading to not significant results. Contrary to this, the results indicate that the use experience of "participating in online community activities through the MIS" is a "virtual life experience," and has been found to be most highly rated in terms of its contribution to the QoL in community life. As reported in mass media, students always use social networking service (SNS) to communicate with others. The results in study might happen because most students nowadays use MIS online community (i.e., virtual connections) under the market environment of very convenient, always-developing MIS services of virtual connections, which were not used so much before. Job status might also influence on the usages of mobile information services. However, it was not included in the survey on students. This variable may be useful to explain the difference of result on work life between 2013 and 2015. Therefore, an 
inclusion of work status and its usage in an analysis as a control variable are recommended in a future study.

The research model fits better with the latest 2015 data than with 2013 data. However, the constructs explained earlier exhibited problems in terms of outdated measurements that needed to be addressed. For the three domains that are not stable, it would be better to update the measurements to reflect recent MIS instead of outdated MIS such as ring-tones because we are dealing with an emerging market that is expected to change.

\section{Summary}

The main objective of this study was to examine the contribution of MIS needs toward improving QoL in Japan. The study also attempted to assess the relationships among the constructs in the model and to test the hypothesis of positive coefficients for each variable. To serve the objective, the study successfully applied PLS-SEM to estimate the parameters of the research model. The results clearly indicated that the relationship between individual contribution and overall contribution is valid and reliable. The findings of the study supported the positive coefficient hypothesis for many variables. Leisure life has the highest influence on Overall Contribution for young Japanese adults. Further, there were some changes between 2013 and 2015, with more positive significant individual domains, which are the following in descending order: cultural life, community life, informational life, home-healthcare life, financial life, trustworthy life, health life, and safety life.

\section{Acknowledgement}

This work was supported by Grants-in-Aid for Scientific Research, No.25245054, the Ministry of Education of the Japanese government.

\section{References}

[1] M.S. Choi, H. Choi, Y.C. Kim, and J. Kim, "An Empirical Study on Post-adoption Behavior of Mobile Data Service with a Focus on Comparison between Services," Korean Marketing Review, Vol. 20, No. 1, 2005, pp. 1-27.

[2] K.C.C. Yang, "Exploring Factors Affecting the Adoption of Mobile Commerce in Singapore," Telematics and Informatics, Vol. 22, No. 3, 2005, pp. 257-277.

[3] T. Rahman, C.M. Ron, and P. Wandschneider, "Measuring the Quality of Life across Countries: A Sensitivity Analysis of Well-being Indices," UNU-WIDERWIDER Research Paper, World Institute for Development Economics Research, Volume:2005/06, 2005.

[4] H. Choi, J. Kim, M. Lee, G. Gaglis, K. Naruse, I. Constantious, E. Fife, and E. G. Mayhew, "Contribution to Quality of Life: Cross-national Validation of New Metrics for Mobile Data Service Technology in Korea and Japan," International Journal of Innovation and Technology 
Management, Vol. 4, No. 2, 2007, pp. 191-208.

[5] Q.M. Ghyas and F.N. Kondo, "How Do Mobile Information Services Improve Quality of Life? The Case of Japanese Students," International Journal of Innovation and Technology Management, Vol. 13, No. 6, 2016; doi:10.1142/S021987701750002X.

[6] D. Gefen, E. Karahanna, and D. W. Straub, "Trust and TAM in Online Shopping: An Integrated Model,” MIS Quarterly, Vol. 27, No. 1, 2003, pp. 51-90.

[7] A. Bhattacherjee and G. Premkumar, "Understanding Changes in Belief and Attitude toward Information Technology Usage: A Theoretical Model and Longitudinal Test," MIS Quarterly, Vol. 28, No. 2, 2004, pp. 229-254.

[8] D.W. Straub, W. Loch, R. Aristo, E. Karahanna, and M. Strite, "Toward a Theory-based Measurement of Culture," Journal of Global Information Management, Vol. 10, No. 81, 2002, pp. 13-23.

[9] S. McCall, "Quality of Life Social Indicators Research," 16: 299-349, 1975.

[10] K.W. Terhune, "Probing Policy Relevant Questions on the Quality of Life," in: The Quality of Life Concept. Washington, DC: Environmental Protection Agency, 1973.

[11]M. J. Sirgy, "Strategic Marketing Planning Guided by the Quality-of-Life (QoL) Concept," Journal of Business Ethics, Vol. 15, No. 3, 1996, pp. 241-259.

[12] K.L. Leung, S.P. Kwok, S.C. Lam, J.F. Lee, R.Y. Yiu, S.S. Ng, P.B. Lai, and W.Y. Lau, "Laparoscopic Resection of Rectosigmoid Carcinoma: Prospective Randomized Trial," Lancet, Vol. 363, 2004, pp. 2224-2229.

[13] E.S. Huebner and R. Gilman, "An Introduction to the Multidimensional Students' Life Satisfaction Scale," Social Indicators Research, Vol. 60, 20002, 115-122.

[14]F.M Andrews and S.B. Withey, "Social Indicators of Well-Being: America's Perception of Life,” Plenum Press, New York, 1976.

[15]H. Choi, S.K. Im, M. Lee, and J. Kim, "Contribution to Quality of Life: A New Outcome Variable for Mobile Data Service," Journal of the Association of Information System, Vol. 8, No. 12, article 1, 2007b, pp. 598-618.

[16] G. Jing and K. Andy, "Mobile Application Development for Senior Citizens," in the Proceedings of Pacific Asia Conference on Information Systems, PACIS 2010, Paper 65.

[17]L. Nguyen, S. Evans, W.D. Wilde, and G. Shanks, "Supporting Information Needs of Senior Citizens in Community Aged Care," in the proceedings of the Australasian Conferences on Information Systems, ACIS 2010, Paper 7.

[18]L. Haddon, "Il ControllodellaComunicazione. Imposizione di Limitiall'uso del Telefono," (ed.) L. Fortunati, Telecomunicando in Europa, Franco Angeli, Milano, 1998.

[19] L. Palen, "Mobile Telephony in a Connected Life," Communications of the ACM, 45, 3: 78$82,2002$.

[20] Strumpel, B. (1973), "Economic Life Styles, Values, and Subjective Welfare-An 
Empirical Approach,” in Family Economic Behavior Problems and Prospects, E. B. Sheldon, ed. Philadelphia: Lippincott.

[21] Kotler, P, “A Generic Concept of Marketing,” Journal of Marketing, Vol. 36. No4, 1972, pp. 6-54.

[22] Maslow, A. H. , "A Theory of Human Motivation," Psychological Review, Vol. 50, No. 4, 1943, pp. 370-396.

[23] M. J. Sirgy, “The Psychology of Quality of Life,” Kluwer, Dordrecht, 2002.

[24] V. D. Heijden (2004), "User Acceptance of Hedonic Information Systems," MIS Quarterly, Vol. 28, No. 4, pp. 695-704.

[25] A. Bhattacherjee, "Understanding Information Systems Continuance: An Expectation-Confirmation Model,” MIS Quarterly, Vol. 25, No. 3, 2001, pp. 351-370.

[26] S.P. de Chenecey, "Putting Brands in their Place," Young Consumers, Vol. 4, No. 2, 2002, pp. 47-50.

[27] W. Pavot and E. Diener, "Review of the Satisfaction with Life Scale," Psychological Assessment, Vol. 5, No. 2, 1993, pp. 164-171.

[28] W.W. Chin, “The Partial Least Squares Approach to Structural Equation Modeling,” In: G. A. Marcoulides (ed), Modern Methods for Business Research, 1998, No.2, pp.295-336.

[29] K.A. Bollen and R. Lennox, "Conventional Wisdom on Measurement: A Structural Equation Perspective," Psychological Bulletin, Vol. 110, No. 2, 1991, pp. 305-314.

[30] J.F. Hair, G.T.M. Hult, C.M. Ringle, and M. Sarstedt, "A Primer on Partial Least Squares Structural Equation Modeling (PLS-SEM),” Thousand Oaks: Sage, 2013.

[31] M. Tenenhaus, V.E. Vinzi, Y.M. Chatelin, and C. Lauro, "PLS Path Modeling," Computational Statistics and Data Analysis, Vol. 48, No. 1, 2005, pp. 159-205. 


\section{Appendix: Survey Questionnaire}

1 Overall, how do you feel about mobile information services (MIS) and the overall
quality of life?
\begin{tabular}{|l|l|}
\hline $\begin{array}{l}\text { Overall Contribu- } \\
\text { tion (ideal; im- } \\
\text { provement; satis- } \\
\text { faction; and } \\
\text { achievement) }\end{array}$ & $\begin{array}{l}\text { I) Using the MIS helps me make my life close to ideal. 2) Using the } \\
\text { MIS improves the general conditions of my life. 3) Using the MIS } \\
\text { helps make my life more satisfying. 4) Using the MIS helps me } \\
\text { achieve important things in my life. }\end{array}$ \\
\hline
\end{tabular}

\subsection{Individual life domains from Choi et al. (2007)}

\begin{tabular}{|c|c|}
\hline Life Domains & Items \\
\hline Cultural & $\begin{array}{l}\text { 1) Purchasing movie or concert tickets over the MIS whenever I want, } \\
\text { improves my cultural life; 2) Making reservations for movies and con- } \\
\text { certs through the MIS while I am out improves my cultural life; 3) } \\
\text { Getting discount vouchers through the MIS before going to a restau- } \\
\text { rant or cinema improves my cultural life; 4) Getting movie infor- } \\
\text { mation through the MIS on the street improves my cultural life; 5) } \\
\text { When it's too bothersome to go to the cinema, reserving tickets } \\
\text { through the MIS improves my cultural life. }\end{array}$ \\
\hline Leisure & $\begin{array}{l}\text { 1) Using the MIS to lift my spirits when I am gloomy improves my } \\
\text { leisure life; 2) Using the MIS to spend my spare time while I am out } \\
\text { helps my leisure life; 3) MIS help me to stay close with my personal } \\
\text { interests, preferences and hobbies which improves leisure life. }\end{array}$ \\
\hline Consumer & $\begin{array}{l}\text { 1) Frequently checking prices through the MIS while I am shopping } \\
\text { improves my life as a consumer; 2) Buying goods through the MIS } \\
\text { instead of actually going out for shopping improves my life as a con- } \\
\text { sumer; } 3 \text { ) Searching for information on goods I want to buy through } \\
\text { the MIS, improves my life as a consumer; 4) Exchanging goods over } \\
\text { the MIS improves my life as a consumer. }\end{array}$ \\
\hline Financial & $\begin{array}{l}\text { 1) Using the MIS to send money electronically to another person when } \\
\text { I am away improves my financial life; 2) Using the MIS to check my } \\
\text { bank account improves my financial life; 3) Using the MIS to buy and } \\
\text { sell stocks/options instantly improves my financial life; 4) Making res- } \\
\text { ervations for trains with low commissions on the MIS improves my } \\
\text { financial life. }\end{array}$ \\
\hline Health & $\begin{array}{l}\text { 1) Recording health data daily through the MIS improves my health } \\
\text { life; 2) Using the MIS to take the medical advice when I can't use a } \\
\text { PC improves my health life; 3) Instead of going to the clinic or hospi- } \\
\text { tal, making an appointment by the MIS will improve my health life. }\end{array}$ \\
\hline Safety & $\begin{array}{l}\text { 1) Using the MIS to search my location when I get lost at a strange } \\
\text { place improves my personal safety; 2) Searching for a safe route to } \\
\text { my destination through the MIS late at night improves my personal } \\
\text { safety; 3) Being in contact with other people through the MIS when I } \\
\text { am alone improves my personal safety. }\end{array}$ \\
\hline
\end{tabular}




\subsection{Individual life domains from Choi et al. (2007) (Cont.)}

\begin{tabular}{|l|l|}
\hline Life Domains & Items \\
\hline Family & $\begin{array}{l}\text { 1) When I am concerned about my family members, searching for } \\
\text { their current location using the MIS improves my family life; 2) Get- } \\
\text { ting in touch with my family members through the MIS to relieve their } \\
\text { worries improves my family life; 3) Sending photos to my family over } \\
\text { the MIS help my family life; 4) To be in constant contact with my } \\
\text { family when I am away improves my family life. }\end{array}$ \\
\hline Friend & $\begin{array}{l}\text { 1) Frequently sending photos to friends over the MIS improves my } \\
\text { friendships; 2) Frequently contacting friends through the MIS im- } \\
\text { proves my friendships; 3) Congratulating friends on their birthday } \\
\text { over the MI improves my friendships. }\end{array}$ \\
\hline Self & $\begin{array}{l}\text { 1) Using the MIS to share my own photos with others improves my } \\
\text { self-expression; 2) Immediately upgrading to the latest services over } \\
\text { the MIS increases my self-esteem; 3) Downloading the latest ring- } \\
\text { tones and logos over MIS increases my self-esteem. }\end{array}$ \\
\hline Community & $\begin{array}{l}\text { 1) Informing members of on-line community meeting dates over the } \\
\text { MIS, improves my community life; 2) Checking bulletin boards and } \\
\text { e-mail from the on-line community over the MIS improves my com- } \\
\text { munity life. }\end{array}$ \\
\hline Work & $\begin{array}{l}\text { 1) Searching for recruiting information through the MIS helps my } \\
\text { work life; 2) Discussing job-related issues with co-workers through } \\
\text { the MIS helps my work life; 3) Working through the MIS when I can't } \\
\text { use a PC helps my work life }\end{array}$ \\
\hline
\end{tabular}

\subsection{Individual life domains from Ghyas and Kondo (2016)}

\begin{tabular}{|l|l|}
\hline Life Domains & Items \\
\hline Trustworthy & $\begin{array}{l}\text { 1) Having trust on the Internet services by MIS, improves my trust- } \\
\text { worthy life; 2) Having trust on paying for the online shopping via } \\
\text { MIS, will improves my trustworthy life; 3) Having trust on MIS } \\
\text { while I am reading, entertaining and getting information via Internet, } \\
\text { will improves my trustworthy life. }\end{array}$ \\
\hline Informational & $\begin{array}{l}\text { 1) MIS helps me to get information of news, weather, maps, etc. } \\
\text { when I need which improves my information life; 2) I can search } \\
\text { personal information through MIS when I need which improves my } \\
\text { personal life; 3) at anytime, anywhere, be searching information at } \\
\text { anytime, anywhere by the MIS is fully useful in order to improve my } \\
\text { informational life }\end{array}$ \\
\hline Home-healthcare & $\begin{array}{l}\text { 1) Using MIS to monitor blood pressure, glucose level, weight, food } \\
\text { calorie etc. by own self when I am home, improves my health life; 2) } \\
\text { Using MIS in home for diet control and medication agenda, etc., im- } \\
\text { proves my health care }\end{array}$ \\
\hline Educational & $\begin{array}{l}\text { 1) Translate words through mobile dictionary anywhere anytime, im- } \\
\text { proves my educational life; 2) Reading newspapers, E-books through } \\
\text { MIS, improves my educational life; 3) to see the education program } \\
\text { by the MIS when I cannot use the PC, will improves my educational } \\
\text { life. }\end{array}$ \\
\hline
\end{tabular}

